\title{
The influence of personality traits and beliefs about medicines on adherence to asthma treatment
}

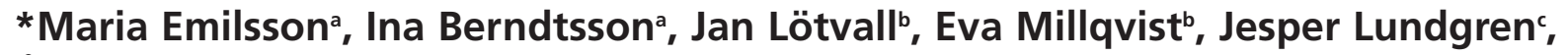 \\ Åke Johansson ${ }^{d}$, Eva Brink ${ }^{e}$ \\ a Department of Nursing, Health and Culture, University of West, Trollhättan, Sweden \\ ${ }^{\mathrm{b}}$ Krefting Research Centre, Department of Internal Medicine, Sahlgrenska Academy, University of Gothenburg, Gothenburg, Sweden \\ ' Department of Psychology, University of Gothenburg, Gothenburg, Sweden \\ ${ }^{d}$ Department of Respiratory Medicine, Central Hospital, Skövde, Sweden \\ ${ }^{\mathrm{e}}$ The Sahlgrenska Academy, Institute of Health and Caring Sciences, University of Gothenburg, Gothenburg, Sweden
}

Received 8th February 2010; revised 6th August 2010; accepted 12th November 2010; online 10th February 2011

\begin{abstract}
Aim: To explore the influence of personality traits and beliefs about medicines on adherence to treatment with asthma medication.

Methods: Respondents were 35 asthmatic adults prescribed controller medication. They answered questionnaires about medication adherence, personality traits, and beliefs about medicines.

Results: : In gender comparisons, the personality traits "Neuroticism" in men and "adherence to medication" were associated with lower adherent behaviour. Associations between personality traits and beliefs in the necessity of medication for controlling the illness were identified. Beliefs about the necessity of medication were positively associated with adherent behaviour in women. In the total sample, a positive "necessity-concern" differential predicted adherent behaviour.

Conclusion: The results imply that personality and beliefs about medicines may influence how well adults with asthma adhere to treatment with asthma medication.

(C) 2011 Primary Care Respiratory Society UK. All rights reserved.

M Emilsson et al. Prim Care Respir J 2011; 20(2): 141-147

doi: 10.4104/pcrj.2011.00005
\end{abstract}

Keywords adherence, asthma, medication beliefs, personality traits, treatment

See linked editorial by Horne on pg 118

\section{Introduction}

The goal of modern asthma care is to gain and maintain control over the illness for long periods. ' When asthma is controlled, patients can keep active, avoid attacks, and prevent troublesome symptoms. Effective asthma control requires regular preventive medication and a response to that medication. Poor receptiveness to asthma medication can be related to individual variability in the dose needed to achieve a response, as well as to low-adherent behaviour in relation to the asthma medication regimen.' In studies of adherence to asthma medication, low-adherent behaviour ranges from $25 \%-42 \%$. $^{2-4}$

The concept of adherence has been developed from the concept of compliance, ${ }^{5}$ but opinions about the definitions of adherence and compliance differ. Compliance and adherence can be viewed as synonyms or as different concepts. ${ }^{6}$ The increased use of the term adherence may be due to the sometimes passive and controlling undertone in the concept of compliance. Adherence emphasises the need for agreement and can be defined as the extent to which the patient's behaviour matches the agreed recommendations from the prescriber and the prescription.?

Many factors have been found to influence medication adherence, and those associated with non-adherent behaviour can be organised into five interacting domains: socioeconomic factors; therapy-related factors; patient-related factors; condition-related factors; and health care system factors.?

\footnotetext{
* Corresponding author: Mrs Maria Emilsson, Department of Nursing, Health and Culture, University West, Trollhättan, SE 46186, Sweden. Tel: +46 (0)520 223983 E-mail: maria.emilsson@hv.se
} 
In the present study, the focus is on patient-related factors i.e., personality traits and beliefs about medicines. Personality traits are defined as "dimensions of individual differences in tendencies to show consistent patterns of thoughts, feelings and actions" ${ }^{8}$ and can be organised into five broad bipolar domains, the so-called Five-Factor Model (FFM). The five domains are: Neuroticism (N), Extraversion (E), Openness (O), Agreeableness (A), and Conscientiousness (C). The personality traits Agreeableness and Conscientiousness have been found to have positive effects on health behaviour. ${ }^{9-10}$ In addition, Conscientiousness was positively associated with adherence to medication regimens. ${ }^{11}$ Neuroticism has been found to have a negative effect on health behaviour, ${ }^{9}$ but the opposite has also been found; people who report high levels in negative affectivity may behave correctly because through their worries about asthma they tend to be more aware of illness-specific symptoms and correctly report and attribute these symptoms to asthma. ${ }^{12}$

According to McCrae's and Costa's "Model of the person", personality traits (understood as underlying tendencies) may explain a person's thoughts, feelings and actions. The association between personality traits and medication adherence may therefore be indirect - i.e., the associations between these characteristics and beliefs about medicines may be of importance to adherent behaviour. ${ }^{5}$ Research documenting associations between personality traits and adherence is limited. In patients with chronic illness ${ }^{13}$ and asthma ${ }^{14}$ adherence to medication regimens has been found to correlate with beliefs about medicines. A theoretical framework has been developed to explain how beliefs about medicine can influence patients' decisions about taking medicines. ${ }^{15}$ Adherent behaviour is likely to be associated with personal beliefs about the specific prescribed medication. Beliefs about the necessity of the medication for controlling illness are balanced against concerns about the possible negative effects of medication. ${ }^{16}$ Adherent behaviour depends on which of the two predominates - beliefs in the necessity of the medication or concerns about possible danger. ${ }^{13}$ In a sample of adult asthma patients, a relationship between higher scores on the necessity scale compared to the concerns scale and medication adherence was identified. ${ }^{17}$ However, we do not fully understand how beliefs about medicines may influence adherent behaviour in relation to asthma medication.

The aim of the present study, therefore, was to explore the influence of personality trait and beliefs about medicines on adherence to asthma medication treatment in men and women.

\section{Methods}

\section{Participants}

Respondents in the present study were recruited from a larger sample in a study on the relationship between asthma and sensory hyperactivity. ${ }^{18}$ Of the larger sample, 42 persons with asthma were invited to participate in the present study. Those who agreed to participate $(n=35,10$ men and 25 women; response rate $83.3 \%$ ) were all prescribed controller medication. The mean age in the group was 52.8 years (SD 14.7). They answered questionnaires about their personality traits, beliefs about medicines and medication adherence. The regional medical ethics committee approved the study.

\section{Questionnaires}

\section{Medication Adherence Report Scale}

The inventory Medication Adherence Report Scale (MARS) is a 5-item self-report scale for assessment of non-adherent behaviour (e.g., 'I forgot to take them' and 'I alter the dose'). The items are rated on a 5 -point Likert scale, ranging from $1=$ 'very often to' $5=$ 'never' (range 5 to 25). Lower scores indicate lower levels of adherent behaviour. ${ }^{19}$ In the present study, Cronbach's alpha for MARS was 0.77 .

\section{NEO Five-Factor Personality Inventory}

The NEO Five-Factor Personality Inventory (NEO-FFI) is a short form of the Revised NEO Personality Inventory (NEO-PI-R), and consists of 60 items, 12 items for each of the domains Neuroticism, Extraversion, Openness, Agreeableness and Conscientiousness. The items are rated on 5-point Likert scale ranging from 0 = 'strongly disagree to' 4 = 'strongly agree' (range 0 to 48). ${ }^{20}$ In the present study, Cronbach's alpha for the five domains ranged from 0.68 to 0.88 .

\section{Beliefs about Medicines Questionnaire}

Beliefs about Medicines Questionnaire specific (BMQ-Specific) assesses respondents' beliefs about their prescribed medication. The BMQ-Specific consists of two subscales: firstly, the specificnecessity scale assesses respondents' beliefs about the necessity of their prescribed medication for controlling their illness and maintaining their health (e.g., "my health, at present, depends on my asthma medication"); and secondly, concerns about the adverse consequences of taking prescribed medication are assessed using the specific-concerns scale (e.g., "I sometimes worry about the long-term effect of my asthma medication"). The items are rated on a 5-point Likert scale ranging from $1=$ 'strongly disagree' to $5=$ 'strongly agree' (range 5 to 25). A higher score on specific-necessity indicates stronger beliefs about the necessity of treatment, and a higher score on specificconcerns indicates stronger concerns. ${ }^{13-16} \mathrm{~A}$ necessity-concerns differential score was calculated by subtracting the specificconcerns scale from the specific-necessity scale (range -20 to 20). A positive differential score indicates stronger necessity beliefs than concerns, and a negative score indicates the contrary - i.e., stronger concerns. ${ }^{13}$ In the present study, Cronbach's alpha for the specific-necessity scale was 0.87 and for the specific-concerns scale 0.78 .

\section{Statistical analysis}

The Statistical Package for the Social Sciences (SPSS) 17.0 was used. Descriptive statistics, frequencies, means, and standard 


\begin{tabular}{|c|c|c|c|c|}
\hline & & $\begin{array}{l}\text { Total } \\
\mathrm{n}=35\end{array}$ & $\begin{array}{l}\text { Men } \\
n=10\end{array}$ & $\begin{array}{l}\text { Women } \\
n=25\end{array}$ \\
\hline Age & $\begin{array}{l}\text { Mean } \\
\text { (SD) } \\
\end{array}$ & $\begin{array}{l}52.85 \\
(14.72) \\
\end{array}$ & $\begin{array}{l}56.70 \\
56.7) \\
\end{array}$ & $\begin{array}{l}51.25 \\
(51.25) \\
\end{array}$ \\
\hline \multirow{4}{*}{$\begin{array}{l}\text { Level of } \\
\text { education }\end{array}$} & Compulsory school & 9 & 1 & 8 \\
\hline & Grammar/High school & 17 & 7 & 10 \\
\hline & College/University & 8 & 1 & 7 \\
\hline & Missing data & 1 & 1 & \\
\hline \multirow[t]{4}{*}{ Occupation } & Employee/Self-employed & 23 & 6 & 17 \\
\hline & Pensioner & 10 & 4 & 6 \\
\hline & Student & 1 & & 1 \\
\hline & Other & 1 & & 1 \\
\hline \multirow{5}{*}{$\begin{array}{l}\text { Medical } \\
\text { treatment }\end{array}$} & Single ICS/LABA inhaler & 17 & 5 & 12 \\
\hline & Separate ICS and & & & \\
\hline & LABA inhalers in & & & \\
\hline & combination & 8 & 1 & 7 \\
\hline & Monotherapy & 10 & 4 & 6 \\
\hline
\end{tabular}

deviations were calculated, and Mann-Whitney's U-test was used to compared means between groups. ${ }^{21}$ The Pitman's test $(<0.05)$ and the Pearson's correlation coefficient (95 percent confident interval) were used to explore associations between variables. Further, linear regression analyses were performed including variables with significant associations with the variable MARS.

\section{Results}

\section{Participants' characteristics}

Of the 35 respondents, 17 were prescribed a combination corticosteroid (ICS)/long-acting $\beta_{2}$-agonist (LABA) inhaler, eight were prescribed ICS and LABA but in separate inhalers, and 10 were prescribed monotherapy (either ICS or LABA). Characteristics of the participants are presented in Table 1.

\section{Personality traits and adherence to the medication regimen}

The mean scores for personality traits and medication adherence measured by NEO-FFI and MARS in this group of asthmatics with controller medication $(n=35)$ are reported in Table 2. No gender differences were identified.

Overall, the five personality traits did not correlate with MARS. However, in gender comparisons, higher scores in men on Neuroticism were associated with lower adherent behaviour scores, and higher scores in men on Conscientiousness were associated with higher adherent behaviour scores (Table 3). Further, in a multiple regression analysis of MARS in men including the independent variables Neuroticism and Conscientiousness, Neuroticism alone explained $52 \%$ ( $R^{2}=0.52$ ) of the variance. Each unit increase in Neuroticism in men decreased medication adherence by 0.41 units $(p<0.01)$. In women, no associations between personality traits and adherent behaviour were identified.

\section{Beliefs about medicines and personality traits}

The mean scores for the Beliefs about Medicines Questionnaire (BMQ) specific-necessity and specific-concerns scales, and the necessity-concerns differential, are presented in Table 2. No gender differences were identified.

In calculations of the necessity-concerns differential, 32 respondents reported positive scores, meaning that their belief about the necessity of taking medication to control their illness was stronger than their concerns regarding the medication. For two of the respondents, the necessityconcerns differential score was zero, and only one person had a negative score $(-1)$.

Associations between the specific-necessity scale and personality traits were found (see Table 4). A positive relationship between Neuroticism and the specific-concerns scale was found in the total group $(r=0.39, p=0.02)$, showing stronger concerns about adverse consequences of taking the prescribed

Table 2. The mean of personality traits, MARS and BMQ $(n=35)$.

\begin{tabular}{lllll} 
& Total (SD) & Men (SD) & Women (SD) & Comparison ( $p$-values men-women) $^{{ }^{1}}$ \\
\hline Neuroticism & $14.91(9.10)$ & $12.00(6.50)$ & $16.08(9.82)$ & n.s. \\
\hline Extraversion & $31.28(6.21)$ & $31.20(3.33)$ & $31.32(7.10)$ & n.s. \\
\hline Openness & $26.63(6.17)$ & $26.60(3.27)$ & $26.64(7.06)$ & n.s. \\
\hline Agreeableness & $34.98(5.85)$ & $34.70(4.57)$ & $35.09(6.37)$ & n.s. \\
\hline Conscientiousness & $35.30(6.29)$ & $36.20(4.71)$ & $34.94(6.88)$ & n.s. \\
\hline MARS & $21.17(3.22)$ & $20.20(3.71)$ & $21.56(3.00)$ & n.s. \\
\hline Specific-Necessity & $18.26(4.60)$ & $19.20(3.88)$ & $17.88(4.88)$ & n.s. \\
\hline Specific-Concerns & $10.49(4.21)$ & $11.40(3.81)$ & $10.12(4.38)$. & n.s. \\
\hline NC/diff2 & $7.77(5.66)$ & $7.80(5.73)$ & $7.76(5.74)$ & n.s. \\
\hline $\begin{array}{l}\text { MARS, Medication Adherence Report Scale; BMQ, Beliefs about Medicines Questionnaire. } \\
\text { Mann-Whitney's U-test; }{ }^{2} \text { Necessity-concerns differential score }\end{array}$ & & \\
\hline
\end{tabular}


M Emilsson et al.

Table 3. Personality traits and BMQ association with MARS.

\begin{tabular}{|c|c|c|c|c|c|c|}
\hline & \multicolumn{2}{|c|}{ Total sample $(n=35)$} & \multicolumn{2}{|c|}{ Men $(n=10)$} & \multicolumn{2}{|c|}{ Women $(n=25)$} \\
\hline & p-values ${ }^{1}$ & $r(95 \% \mathrm{Cl})^{2}$ & p-values ${ }^{1}$ & $r(95 \% \mathrm{Cl})^{2}$ & $p$-values ${ }^{1}$ & $\mathrm{r}(95 \% \mathrm{Cl})^{2}$ \\
\hline Age & $>0.30$ & $-0.06(-0.39$ to 0.29$)$ & 0.12 & $0.57(-0.09$ to 0.88$)$ & 0.25 & $-0.26(-0.60$ to 0.16$)$ \\
\hline Neuroticism & 0.06 & $-0.34(-0.61$ to -0.01$)$ & 0.03 & $-0.72(-0.93$ to -0.17$)$ & 0.15 & $-0.32(-0.63$ to 0.09$)$ \\
\hline Extraversion & 0.30 & $0.19(-0.15$ to 0.49$)$ & $>0.30$ & $0.26(-0.44$ to 0.76$)$ & $>0.30$ & $0.20(-0.21$ to 0.55$)$ \\
\hline Openness & $>0.30$ & $-0.14(-0.45$ to 0.20$)$ & 0.22 & $-0.46(-0.85$ to 0.24$)$ & $>0.30$ & $-0.09(-0.47$ to 0.32$)$ \\
\hline Agreeableness & $>0.30$ & $0.00(-0.34$ to 0.33$)$ & 0.15 & $0.52(-0.16$ to 0.87$)$ & $>0.30$ & $-0.19(-0.54$ to 0.22$)$ \\
\hline Conscientiousness & 0.16 & $0.26(-0.08$ to 0.54$)$ & 0.04 & $0.67(0.07$ to 0.92$)$ & $>0.30$ & $0.17(-0.24$ to 0.53$)$ \\
\hline Specific-Necessity & 0.03 & $0.38(0.05$ to 0.63$)$ & $>0.30$ & $0.35(-0.36$ to 0.80$)$ & 0.03 & $0.45(0.07$ to 0.72$)$ \\
\hline Specific-Concerns & $>0.30$ & $-0.16(-0.47$ to 0.19$)$ & 0.15 & $-0.53(-0.87$ to 0.16$)$ & $>0.30$ & $0.01(-0.39$ to 0.41$)$ \\
\hline $\begin{array}{l}\text { Necessity-concerns } \\
\text { differential score }\end{array}$ & 0.02 & $0.42(0.10$ to 0.66$)$ & 0.09 & $0.59(-0.07$ to 0.89$)$ & 0.09 & $0.36(-0.04$ to 0.66$)$ \\
\hline
\end{tabular}

MARS, Medication Adherence Report Scale; BMQ, Beliefs about Medicines Questionnaire

${ }^{1}$ Pitmans test; ${ }^{2}$ Pearson's r

Table 4. Correlations between specific necessity scale and personality traits.

\begin{tabular}{lllllll} 
& Total sample $(\mathrm{n}=35)$ & Men $(\mathrm{n}=10)$ & & Women $(\mathrm{n}=25)$ \\
\hline & $\mathrm{p}$-values & $\mathrm{r}^{1}$ & $\mathrm{p}$-values & $\mathrm{r}^{1}$ & $\mathrm{p}$-values & $\mathrm{r}^{1}$ \\
\hline Neuroticism & 0.051 & -0.33 & 0.69 & -0.14 & 0.09 & -0.35 \\
\hline Extraversion & 0.32 & 0.17 & 0.90 & -0.05 & 0.31 & 0.21 \\
\hline Openness & 0.23 & 0.21 & 0.90 & -0.04 & 0.23 & 0.25 \\
\hline Agreeableness & 0.16 & 0.24 & 0.02 & 0.71 & 0.47 & 0.12 \\
\hline Conscientiousness & 0.047 & 0.34 & 0.25 & 0.40 & 0.32 \\
\hline${ }^{1}$ Pearson's & & & & &
\end{tabular}

Table 5. Correlation between necessity-concerns differential score and personality traits.

\begin{tabular}{|c|c|c|c|c|c|c|}
\hline & Total samp & e $(n=35)$ & Men $(n=10)$ & Women $(n=25)$ & & \\
\hline & p-values & $r^{1}$ & p-values & $r^{1}$ & p-values & $\mathrm{r}^{1}$ \\
\hline Neuroticism & $<0.01$ & -0.56 & 0.11 & -0.53 & $<0.01$ & -0.60 \\
\hline Extraversion & $<0.01$ & 0.44 & 0.43 & 0.28 & 0.01 & 0.49 \\
\hline Openness & 0.04 & 0.35 & 0.39 & -0.31 & 0.02 & 0.48 \\
\hline Agreeableness & 0.07 & 0.31 & 0.053 & 0.62 & 0.28 & 0.23 \\
\hline Conscientiousness & $<0.01$ & 0.45 & 0.03 & 0.68 & 0.05 & 0.40 \\
\hline
\end{tabular}

medication; however, this association was found in men ( $r=0.65$, $\mathrm{p}=0.04$ ), but not in women. Also, a negative relationship between Extraversion and the specific-concerns scale was found in the total group $(r=-0.40, p=0.02)$. This association was found in women in the gender comparison ( $r=-0.41, p=0.04$ ). Associations between the necessity-concerns differential score and personality traits are shown in Table 5 .

Beliefs about medicines and adherence to medication regimens

A positive relationship between MARS and the specificnecessity scale was found, showing that a stronger belief in the necessity of medication for controlling illness was associated with higher adherence. This association was found in women, but not in men (Table 3). In addition, a simple linear regression analysis showed that in women, the scale specific-necessity explained $20 \%\left(R^{2}=0.20\right)$ of the variance in MARS. In women each unit increase in the specific-necessity scale increased adherence by 0.28 units $(p<0.01)$. The scale specific-concerns was not related to medication adherence in women or in men. A positive relationship between the necessity-concerns differential and MARS was found in the total sample (Table 3). 
Finally, in a multiple regression analysis of MARS in the total sample, with the independent variables specific-necessity scale and necessity-concerns differential (see Table 5), the latter variable explained the variance in MARS $\left(R^{2}=0.17\right)$. The specific-necessity scale was not associated with MARS. Each unit increase in the necessity-concerns differential increased adherence by 0.23 units $(p<0.01)$.

\section{Discussion}

We have shown that the personality trait Neuroticism in men was associated with lower adherence to medication. Regarding beliefs about medicines, a belief in the necessity of medication for controlling illness was associated with a higher degree of adherence. In addition, a positive relationship between the necessity-concerns differential and adherence was found, indicating that having stronger beliefs about the necessity of treatment compared to concerns about negative consequences may increase adherence.

Our finding that Neuroticism in men was associated with a lower degree of adherent behaviour was not supported in an earlier study, ${ }^{22}$ but during the past decade asthma medication regimens have developed further and it may be difficult to compare the present results with findings from a study conducted more than ten years ago. A person scoring high in Neuroticism has a tendency to experience fear, be concerned and feel anxious. ${ }^{8}$ One possible explanation for the reason why men scoring high in Neuroticism reported low adherent behaviour may be that they also scored high on the BMQ specific-concerns scale. This could mean that they were worried about the negative consequences of medications and therefore refrained from following the prescribed medication regimen.

There is one previous study that focuses on the significance of personality in relation to medication adherence, ${ }^{23}$ and there are some studies on beliefs about medicines ${ }^{13,14,17,24-26}$ in relation to adherence to treatment with asthma medication. Earlier research on patient-related factors and adherence has focused on the importance of knowledge ${ }^{27}$ and self-efficacy. ${ }^{28}$ Further, the health beliefs model states that a person's behaviour is related to beliefs about different illness perception aspects. However, this model has yielded only weak positive relationships between patients' beliefs and behaviour. ${ }^{29}$ The trans-theoretical model states that the provider of information should tailor the information to the patient's current state in order to improve adherence. ${ }^{30}$ Since the adherent behaviour phenomenon is multidimensional, there are several other theoretical perspectives that could be discussed. ${ }^{31}$ Common to them is that personality traits have not been taken into account - hence our rationale for investigating associations between personality traits, beliefs about medicines and adherence research.

One limitation of the present study was the small sample size, and therefore we are cautious about drawing conclusions. However, the association found between Neuroticism and adherence in adult asthmatics appears to be a useful finding. Findings from one study on heart failure patients showed an association between compliant behaviour and Neuroticism, which may indicate that persons scoring high on that personality trait can have problems with compliance. ${ }^{32}$ Therefore, exploring the relation between personality traits and medication adherence would seem to be an important issue for healthcare professionals. Probably due to the small sample size, we could not completely confirm the findings from other studies that Conscientiousness tends to be positively associated with adherent behaviour in relation to medication treatment. ${ }^{11,23,33,34}$ In the present analyses, Conscientiousness was first correlated with adherence, but was not shown further to be a predictor of adherent behaviour in the regression model. Also, medication adherence was measured by a self-report questionnaire which possibly could produce higher adherence scores compared to, for example, electronic monitor measures. However, selfreports are simple and inexpensive and could therefore be justified. Despite a large number of studies, the question of how best to measure adherence has not been answered. ${ }^{35}$

In the present study, beliefs about medicines were found to be possible indicators of adherent behaviour, such that a stronger belief in the necessity of the medication in women and the necessity-concerns differential in the total sample were associated with higher adherence. This result is in line with earlier studies showing that when beliefs in the necessity of medication are stronger than concerns, the adherent behaviour will increase. ${ }^{13,17}$ The most adherent individuals are those who accept the necessity of medication and have low concerns about potential adverse consequences. ${ }^{17,24}$

A study by Smith, Mitchell and Bowe ${ }^{36}$ showed that a patient-centred asthma education programme led to fewer health care re-attendances than a standardised education programme. In our opinion, personality traits could be used to guide efforts to educate asthma patients. The results add knowledge about the relationships between personality traits, beliefs about medicines, and adherent behaviour in adult asthma patients. Such knowledge can be used as a basis for developing individualised treatment plans tailored to patients' personality and their beliefs about medicines. The present results indicate that difficulties with low medication adherence can be anticipated beforehand, given the patient's personality characteristics and medication beliefs. For instance, a person who is generally neurotic is likely to experience barriers to taking medication grounded on concerns about potential adverse effects and the way he/she balances the perceived benefit beliefs (necessity) against the perceived risks (concerns). If healthcare professionals were to 


\section{Discussion Summary}

a) Difficulties in this study: The sample size was small, and therefore we are cautious about drawing conclusions.

b) Alternative methodologies: Medication adherence can be measured in different ways, e.g. electronic monitor measures.

c) New questions: Would a trial in a larger sample further explore the relationship between personality traits and medication adherence?

d) Lessons: Results indicate the need for a personal approach to improve adherent behavior and enhance understanding of the necessity of asthma medication.

reflect on such dilemmas in a person scoring high on the trait neuroticism, and can reduce the patient's anxiety and worries, some adherence problems could be reduced through individualised communication and support. On the other hand, a conscientious person may more likely balance the beliefs about necessity and concerns and may not need the same specific treatment. This implies that assessment of personality traits and beliefs about medicines may prove to be a useful part of care-planning.

\section{Conflicts of interest}

None to declare.

\section{Funding}

This study was supported by the Herman Krefting Foundation for Asthma and Allergy Research, Sweden, and The Swedish Asthma and Allergy Association.

\section{References}

1. Global Initiative for Asthma (GINA). Global Strategy for Asthma Management and Preventation. Revised 2009. http://www. ginasthma.com.

2. Janson SL, Earnest G, Wong KP, Blanc PD. Predictors of asthma medication nonadherence. Heart Lung 2008;37(3):211-18. http://dx.doi.org/10.1016/ j.hrtlng.2007.05.014

3. Joshi AV, Madhavan SS, Ambegaonkar A, Smith M, Scott VG, Dedhia H. Association of medication adherence with workplace productivity and healthrelated quality of life in patients with asthma. J Asthma 2006;43(7):521-6. http://dx.doi.org/10.1080/02770900600857010

4. Bender BG, Long A, Parasuraman B, Tran ZV. Factors influencing patient decisions about the use of asthma controller medication. Ann Allergy Asthma Immunol 2007;98(4):322-8

5. Horne R. Compliance, adherence, and concordance: implications for asthma treatment. Chest 2006;130:65S-72S. http://dx.doi.org/10.1378/chest.130. 1_suppl.65S

6. Haynes RB, Ackloo E, Sahota N, McDonald HP, Yao X. Interventions for enhancing medication adherence (Review). Cochrane Database Syst Rev. 2005; (4 Art No.:CD000011). http://dx.doi.org/10.1002/14651858.CD000011.pub2

7. World Health Organization. Adherence to long-term therapies: evidence for action. Geneva: World Health Organization, 2003

8. McCrae RR, Costa PT. Personality in adulthood: a five-factor theory perspective. 2. ed., New York: Guilford Press, 2002

9. Booth-Kewley S, Vickers RR. Associations Between Major Domains of
Personality and Health Behavior. J Pers 1994;62(3):281-98.

10. Ingledew DK, Brunning S. Personality, preventive health behaviour and comparative optimism about health problems. J Health Psychol 1999;4(2):193208.

11. Christensen AJ, Smith TW. Personality and patient adherence: correlates of the five-factor model in renal dialysis. J Behav Med 1995;18(3):305-13. http://dx.doi.org/10.1007/BF01857875

12. Mora PA, Halm E, Leventhal H, Ceric F. Elucidating the relationship between negative affectivity and symptoms: the role of illness-specific affective responses. Ann Behav Med 2007;34(1): 77-86. http://dx.doi.org/10.1007/ BF02879923

13. Horne R, Weinman J. Patients' beliefs about prescribed medicines and their role in adherence to treatment in chronic physical illness. J Psychosom Res 1999; 47(6):555-67. http://dx.doi.org/10.1016/S0022-3999(99)00057-4

14. Byer B, Myers LB. Psychological correlates of adherence to medication in asthma. Psychol Health Med 2000;5(4):389-93.

15. Horne R. In. Petrie KJ, Weinman J, eds. Perceptions of health and illness: current research and applications. Harwood Academic: Amsterdam; United Kingdom, 1997:155-212.

16. Horne R, Weinman J, Hankins M. The Beliefs about Medicines Questionnaire: The development and evaluation of a new method for assessing the cognitive representation of medication. Psychol Health 1999;14(1):1-24.

17. Menckeberg $T$, Bouvy ML, Bracke $M$, et al. Beliefs about medicines predict refill adherence to inhaled corticosteroids. J Psychosom Res 2008;64(1):47-54. http://dx.doi.org/10.1016/j.jpsychores.2007.07.016

18. Johansson, A. Airway sensory hyper reactivity linked to capsaicin sensitivity: definitions and epidemiology. Göteborg: Dissertation. Department of Internal Medicine, Institute of Medicine at Sahlgrenska Academy, University of Gothenburg, 2008.

19. Horne R, Hankins M. The Medication Adherence Report Scale (MARS). Brighton UK: University of Brighton, 2004.

20. Costa Jr PT, McCrae RR. Revised NEO Personality Inventory (NEO PI-R) and NEO Five-Factor Inventory (NEO FFI) Professional Manual, Odessa, FL: Psychological Assessment Resource, 1992.

21. Brace N, Kemp R, Snelgar R. SPSS for psychologists: a guide to data analysis using SPSS for Windows. 3.ed. Basingstoke: Palgrave Macmillan, 2006.

22. Put C, Van den Bergh O, Demedts M, Verleden G. A study of the relationship among self-reported noncompliance, symptomatology, and psychological variables in patients with asthma. J Asthma 2000;37(6):503-510.

23. Axelsson M, Emilsson M, Brink E, Lundgren J, Torén $K$, Lötvall J. Personality, adherence, asthma control and health-related quality of life in young adult asthmatics. Respir Med 2009;103:1033-40. http://dx.doi.org/10.1016/ j.rmed.2009.01.013

24. Tibaldi G, Clatworthy J, Torchio E, Argentero P, Munizza C, Horne R. The utility of the Necessity-Concerns Framework in explaining treatment non-adherence in four chronic illness groups in Italy. Chronic IIIn 2009;5:129-33. http://dx.doi.org/10.1177/1742395309102888

25. Le TT, Bilderback A, Bender B, et al. Do asthma medication beliefs mediate the relationship between minority status and adherence to therapy? J Asthma 2008;45(1):33-7. http://dx.doi.org/10.1080/02770900701815552

26. Horne $R$, Weinman J. Self-regulation and self-management in asthma: exploring the role of illness perceptions and treatment beliefs in explaining non-adherence to preventer medication. Psychol Health 2002;17(1):17-32. http://dx.doi.org/10.1080/08870440290001502

27. Levy ML, Robb M, Allen J, Doherty C, Bland JM, Winter RJD. A randomized controlled evaluation of specialist nurse education following accident and emergency department attendance for acute asthma. Respir Med 2000 94(9):900-08. http://dx.doi.org/10.1053/rmed.2000.0861

28. Scherer YK, Bruce S. Knowledge, attitudes, and self-efficacy and compliance with medical regimen, number of emergency department visits, and 
hospitalizations in adults with asthma. Heart Lung 2001;30(4):250-7. http://dx.doi.org/10.1067/mhl.2001.116013

29. Dunbar-Jacob J, Gemmell LA, Schlek EA.Predictors of adherence: Patient Characteristics. In: Shumaker A, ed. The handbook of health behavior change. New York: Springer Pub, 2008. P.397-410.

30. Prochaska JO, DiClemente CC. Stages and processes of self-change of smoking: Toward an integrative model of change. J Consult Clin Psychol 1983;51(3):390-5.

31. Oser ML. Patient education to promote adherence to treatments. In. O'Donohue WT, Levensky ER, ed. Promoting treatment adherence. London: Sage, 2006.P.85-118

32. Evangelista LS, Berg J, Dracup K. Relationship between psychosocial variables and compliance in patients with heart failure. Heart Lung 2001;30:294-301. http://dx.doi.org/10.1067/mhl.2001.116011
33. O'Cleirigh C, Ironson G, Weiss A, Costa Jr PT. Conscientiousness predicts disease progression (CD4 number and viral load) in people living with HIV. Health Psychol 2007;26:473-80. http://dx.doi.org/10.1037/0278-6133.26.4.473

34. Stilley CS, Sereika S, Muldoon MF, Ryan CM, Dunbar-Jacob J. Psychological and cognitive function: predictors of adherence with cholesterol lowering treatment. Ann Behav Med 2004;27:117-24.

35. DiMatteo MR. Variation in patients' adherence to medical recommendations: a quantitative review of 50 years of research. Med Care 2004;42(3):200-09. http://dx.doi.org/10.1097/01.mlr.0000114908.90348.f9

36. Smith S, Mitchell C, Bowler S. Standard versus patient-centred asthma education in the emergency department: a randomised study. Eur Respir J 2008;31(5):990-7. http://dx.doi.org/10.1183/09031936.00053107

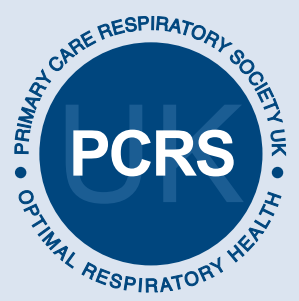

\section{PCRS-UK National Primary Care Respiratory Conference} Delivering Quality Respiratory Care Today Raising the Bar 7th-8th October 2011 - Telford International Centre

\section{CALL FOR ABSTRACTS}

\section{PCRS-UK Clinical and Scientific Abstracts 2011}

Our aim is to showcase community-based respiratory research and innovative clinical/service developments through a series of abstract-based sessions running throughout the two-day conference. We therefore invite submission of abstracts related to the management of respiratory and respiratory-related allergic diseases, and the delivery of respiratory services, in primary care.
Categories for Abstract submission:

- Asthma

- Allergy

- COPD

We are therefore inviting submission of abstracts for oral presentation in the research and audit sessions, and poster submissions for display in the exhibition area, throughout the 2011 PCRS-UK conference.

\section{DEADLINE FOR SUBMISSION OF ABSTRACTS IS 20TH JUNE 2011}

For details on submission dates, how to get help, how to submit your abstract, and guidance on artwork together with notes for contributors, please log on to https://www.pcrs-uk.org/abstracts/

The PCRS-UK is willing to offer support to those without previous experience of submitting posters. 